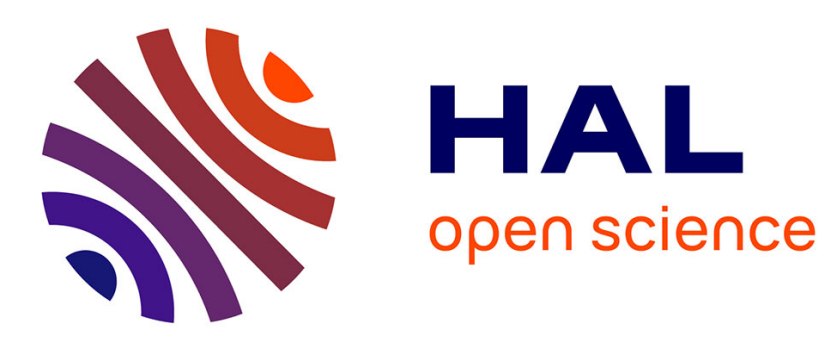

\title{
Introduction - Bodies on Trial: Performances and Politics in Medicine and Biology
}

\author{
Madeleine Akrich, Marc Berg
}

\section{To cite this version:}

Madeleine Akrich, Marc Berg. Introduction - Bodies on Trial: Performances and Politics in Medicine and Biology. Body \& Society, 2004, 12, pp.1-12. halshs-00122124

\section{HAL Id: halshs-00122124 \\ https://shs.hal.science/halshs-00122124}

Submitted on 27 Dec 2006

HAL is a multi-disciplinary open access archive for the deposit and dissemination of scientific research documents, whether they are published or not. The documents may come from teaching and research institutions in France or abroad, or from public or private research centers.
L'archive ouverte pluridisciplinaire HAL, est destinée au dépôt et à la diffusion de documents scientifiques de niveau recherche, publiés ou non, émanant des établissements d'enseignement et de recherche français ou étrangers, des laboratoires publics ou privés. 


\title{
Bodies on Trial: Performances and Politics in Medicine and Biology
}

\section{Introduction}

\author{
Marc Berg and Madeleine Akrich \\ Body \& Society, 10, pp.1-12.
}

This special issue, devoted to the question of the body in medicine and biology, brings together a group of authors whose roots lie within the field of science and technology studies (STS), and at the intersections of STS with medical sociology and medical anthropology. As testified by the vitality of Body \& Society, 'the body' is in the center of revived attention in the social sciences and humanities. Medical sociology and anthropology has produced important contributions to the renewal of the body's conceptualisation ${ }^{1}$, and feminist studies have put the construction of 'sex' and its relationships to gender center stage. ${ }^{2}$ Some authors even argue that social theory should be re-centered around the notion of 'embodiment' or a similar concept. ${ }^{3}$ What kind of insights can STS studies bring into this set of interrogations? Briefly said, STS approaches may help escape the pull between two powerful theoretical/philosophical positions that have, for some time, been at work in conceptualizing the body: phenomenological approaches on one side, and constructivist approaches on the other.

The field of STS gained momentum in the 1980s by turning empirical research methods on the production of scientific facts. Taking an 'agnostic' stance, ethnographers entered laboratories and started to investigate 'science in the making'. Directly questioning traditional philosophical viewpoints on the epistemological uniqueness of 'doing science', these researchers argued that the attribution of this unique epistemological quality was a thoroughly social process. ${ }^{4}$

This reinterpretation of the nature of scientific development subsequently led to increased attention to the social nature of technological development, the place of scientific expertise in policy making, science policy, medical sociology, and so forth. Among these lines of investigation, one strong strand has most potential to contribute to discussions on the 'body': those approaches that have focused on the materiality of technoscientific practice. Starting with a deep interest in the ways experiments and technological 
development are social practices yet cannot be simply reduced to social interactions, many authors have started to investigate the very nature of 'matter', 'objects' and 'embodiment'.

Centralizing 'embodiment' without presupposing an a-historical, biologically grounded 'body' is, of course, already a familiar challenge in studies of the body. ${ }^{6}$ Yet starting from its interest in technoscientific objects, STS has emphasized the central role of 'objects' and 'materiality' in any viable social theory. It has emphasized the material heterogeneity of the networks that constitute society, and has stressed the active, mediating role of objects and artefacts in shaping categories previously deemed to be 'purely social': human interactions, organizations, professions, expertise, and so forth. ${ }^{7}$ STS's emphasis on the material heterogeneity of practices and its struggle with the concurent historicity and durability of 'objects' and 'matter', when applied to the body ${ }^{8}$, provides the analyst with theoretical tools allowing to meet the challenge drawn by Donna Harraway: to acknowledge the body's active status as agent without implying its immediate, pre-fixed presence, in other words considering it as a 'material-semiotic generative node' which is fundamentally both discursive and material, both historical and real (Haraway 1991, 197-201). ${ }^{9}$

A second distinctive feature of STS, its agnosticism, gives it a potent recourse when confronted with the body question: STS does not need, and even actively refuses, to make any hypothesis about the nature of the objects it studies. On the contrary, it considers this 'nature' an empirical question. In this perspective, the analysis does not privilege any 'kind' of body over the others, the body as represented in scientific discourse, the body as experienced by the patient, the body as locus of medical practices, the body as inscribed in medical records, etc. Instead it tries to trace the intricacy of all these bodies, describing how each 'body 'is specifically connected to a set of practices, material devices and rhetorical genres, which include modalities defining the way it relates to other 'bodies'. ${ }^{10}$

In this special issue, thus, we are first of all committed to bracketing out pre-fixed notions of what a body might be, and how it might be delineated. As just pointed out, these notions should not be seen as the starting point of a theoretical analysis, but as the empirical result of practices, as the effect of the development of specific networks (Callon and Law 1995). What we attempt to do here, then, might be summarized as investigating whether a reconfigured notion of 'embodiment' might serve as a fruitful bridge between the historical specificity of bodies and the lived, 'first person' experience of having/being a body. Embodiment, so we would claim, can be seen as a process rather than as a pre-given biological fact; it can be empirically studied as the outcome of historical processes rather than posited as the elementary starting point for social theorizing. Redefined in this way, embodiment points both at the process of the emergence of a specific (concept of the) body, 
and at the real-time having/being of this body. This process can be conceptualized as a series of trials, as emergences of specific characteristics in and through the confrontation with features of the network of which the emerging body is a part.

To unravel the multitude of issues that are at stake in such an approach, this special issue is divided into three parts. The first part, Performing Bodies, focuses on the production and performance of bodies within medical and biological practices. The three articles elaborate a performative notion of 'bodies' and 'embodiment'. This implies the already mentioned notion that 'the body' and 'body boundaries' are not taken as selfevident, a-historical concepts, but that they are seen as historically constructed. It makes no sense to try to debate the essential nature of the body, or, for that matter, to implicitly posit a pre-existing 'wholeness' of the body which is subsequently undone and reduced through for example 'medical technology' (cf. Berg and Mol 1998, Komesaroff (1995)). The ontology of bodies is exactly what is taken to be an empirical matter - the outcome of the trials. In their study, for example, Marc Berg and Paul Harterink argue that Foucault's modern, medical body might have been a reality in research practices at the beginning of this century, but that it certainly did not figure in the everyday medical wards and offices of that time. The emergence of this body in clinical practice, they argue, was closely tied to the emergence of a technology that stands central in its performance: the patient centered medical record. Berg and Harterink argue that this body is the effect of a historical development, and that it is in fact a modest medical technology such as the medical record that has helped create it.

This construction of bodies and body boundaries, moreover, is not something that has been done and is now achieved. The notions of 'performance' and 'embodiment' can be seen to point at the ongoing nature of the process: these are entities that have to be continually performed and maintained for them to persist. Bodies, Annemarie Mol and John Law argue in their article on the performance of hypoglycaemia, are enacted. Their specific reality stands or falls with the active presence of devices, routines, modes of self-monitoring, and so forth. 'Bodies' are not interpreted, not pre-existing, not merely the concrete instantiation of 'larger' historical developments, but performed, in concrete practices and in highly specific ways.

In addition, bodies and body-boundaries are seen to be variable entities which can and are performed differently in different cultures, different practices, and sometimes even within one practice. Law and Mol, for one, stress that bodies as such hardly seem to come into play when one studies the performance of hypoglycaemia. They encounter blood samples, sugar levels and accounts of life styles - but these do not unequivocally sum up to 
any one 'body'. The 'body as a whole', like the unified Self and the very existence of a 'first person' perspective are not only achievements rather than a priori givens - they are only rare occurences. In a similar mode, Madeleine Akrich and Bernike Pasveer analyze women's narratives on the experience of giving birth. Drawing upon a situation in which the body is often considered as a 'naturally' acting entity, they display the long series of mediations, including technologies, that perform this acting body for the woman herself. Instead of invariable body/self divides, they argue, narratives constitute varying dichotomies between a body and an embodied self, none of which is stable. Both Mol and Law and Akrich and Pasveer, then, stress that we cannot speak of 'the' body. We face, rather, a multiplicity of partial instantiations of bodies, whose interconnections are always tentative and never self-evident.

Finally, all the authors in this part share the notion that this performance is achieved by associations of heterogeneous entities. The notion of performance does not imply that someone or something is 'doing' the performance (cf. Butler 1993). Hypoglycaemia or childbirth is not 'performed' by individuals - as actors 'performing' roles -, nor is it 'produced' in 'discourse' (as a text 'speaking' its subjects). It is not a social construction, nor a text; things, practices, architectures play a core role in its construction (as is exemplified by Berg and Harterink's emphasis on the patient centered medical record). The body is 'done' by the practice of blood sugar measurement, for one, and by the midwife, the instruments in the delivery room, the partner, and so forth. Only in the interrelation of these entities does a specific body arise. ${ }^{11}$ This implies that performance cannot be described as re-presentation in a formal sense: that is to say, 'performance', for the authors gathered here, is not the collective production and reproduction of pre-defined categories and social roles.

In the second part, Body as Mediator, the performance of specific bodies is no longer the primary point of attention. In this part, authors focus on how bodies are implicated in the production of biological knowledge (Despret), in the treatment of drug addicts (Gomart), and in the practices of organ procurement in 'living cadavers' (Lock). Bodies, here, are by-product and mediator: they are one of the elements that come to play in the performances at stake, yet they can only be in that position because they are themselves affected by this performance.

Some social scientists have criticized western medical practices as drawing upon and performing a dualist definition - body/mind - of the person. The different contributions presented in this part show that this dualist definition is not a permanent one, and that the patient is himself or herself active in producing if not this dualism than at least a whole array 
of modes of body presences reaching from objectivation to subjectivity. Moreover, the positioning of the body in relations of knowledge production or treatment often takes unexpected forms, challenging traditional notions of 'passive' subjects 'undergoing' treatment and being 'objectivied' in order to be medically 'known'.

In her study of methadone substitution treatment, Emilie Gomart touches upon these issues. She focuses on the intricate relations between drugs and human agency. In her case, the point is exactly that under certain conditions the use of drugs such as methadone do not 'reduce' users to 'addicted bodies'. She problematizes received oppositions of free will versus determination (by drugs or therapists); of agency versus material constraints; of selfcontrol versus control by drugs. The question of drug use does not revolve around the determination of bodies (or minds, for that matter) by pharmacological substances. Gomart argues that her topic necessitates a new vocabulary to describe modes of human agency because the usual sociological terms of determinism, control, influence, manipulation (by substance or therapist or user) are not sufficient. These terms can only describe drug or methadone use as a limitation to true subject-hood, while 'subjects', in Gomart's analysis, can only exist in and through their constant 'submission' to the entities that surround and perform them.

Related to these issues is the question what this repositioning of the body implies for the way we conceptualize and evaluate the knowledge that results from these interactions. If the body is neither a traditional 'object' or 'subject' of knowledge practices, but figures as an active mediator upon which these practices draw, what is then the epistemological consequence of this? Vincianne Despret's article tackles this complex question head on. Her paper discusses animal experiments, and discusses the question how scientific knowledge of animal behavior is possible, and what type of relationships specific knowledge practices forge between the experimenter, the animal, and the knowledge produced. It topicalizes the different ways the experimenter and the animal can be embodied in experiments - and Despret passionately argues for an epistemology in which a care for the bodies studied, and a relation of mutual 'affectuation' between experimenter and object, produces knowledge that can take us by surprise. In her paper, then, it is again 'bodies' that are at stake - but here as the objects and subjects of knowledge. Good scientific knowledge about 'bodies', she argues, is based upon experiments that maximize the chances of the object of study to transform the expected results - and ultimately, mediate the experimenter him- or herself.

Both Despret and Gomart obviously encounter bodies as one of their core mediating actants - yet their point is that the very concept of the 'body' (what it is, how it acts) is itself 
at stake in the practices they study. A 'final' theory of the body could never be their entry point, since it is just one of the phenomena produced in the trials of addiction treatment and the experiments of animal behavior research. Drawing on a different theoretical framework, Lock's study of 'living cadavers' is a similar case in point. Lock focuses on the practices of organ procurement (for transplantation purposes) in brain dead subjects, and elucidates the striking differences between the way 'brain dead bodies' are handled and conceptualized in the United States and in Japan. In the former case (and in many European countries), the 'commodification' of body parts is well advanced, and it is widely accepted that a brain dead person is 'dead' for all legal, ethical and social purposes. In Japan, however, these 'warm bodies', with regular heat beats and many intact reflexes are not unequivocally considered 'dead' at all, and the procurement of organs from such bodies is rare and highly contested. Lock elucidates the subtleties of these differences through interviews with ICU physicians and nurses, amongst others, and explains these differences through an elaboration of specific historical developments, differences in legal considerations, religious backgrounds, the role of the media and so forth. Lock does not focus explicitly on the materially heterogeneous performance of bodies: her analysis articulates the culturally different practices around 'living cadavers' and is similarly not explicitly concerned with the mediating role that these cadavers themselves play in these very practices. Yet these concerns are not far from the surface: the 'brain dead' condition can only persist with 'healthy' organs through medical interventions, and the peculiar condition of these 'cadavers' does play a core role in the way these different cultures enroll them within the charged debates around organ procurement.

The third and last part, Body Collective, elaborates an issue that has been more or less present in the papers of this volume: the political nature of the performance of specific bodies. Often, the politics at stake in topicalizing 'bodies' is a struggle for the wholeness of bodies, or for the integrity of body-boundaries. In such cases, the body's wholeness and unity is taken as a primary characteristic, and its materiality is taken as a possible 'grounding' for resistance and critique. So 'invasion' of female bodies by reproductive technologies that perform the fetus as 'subject' can be criticized by pointing at the female bodies that are thereby reduced or intervened upon. Likewise, patients' dependence on medical drugs and technologies can be described as the gradual 'emptying out' of the lived body by Technology, and as the unfortunate 'medicalization' of previously 'whole' lives. This recourse to the integrity and wholeness of bodies has been a powerful and succesful political strategy for feminists and ethicists, amongst others, in claiming e.g. basic reproductive rights and, more generally, the right of the individual to decide about any intervention that deliberately affects his/her body. 
At the same time, however, this position is more and more contested. The authors joined in this special issue underwrite critiques of authors such as Haraway that the political grounding that this supposed 'wholeness' and 'integrity' yields is rather problematic (1991). For one, it reinvents the body as a universal, a-historical category - and such categories have never been very generous towards women or people of colour, to name a few. In addition, the constructivist, performative position elaborated here makes any recourse to such a pre-existing entity impossible. If every 'wholeness' is a historically specific and performed 'wholeness', the question becomes which more or less 'whole' body is preferred, and by whom? Different practices within medicine and biology perform different bodies, and these differences may be a much more important point of entry for political struggle than the worn critique of the impoverished 'medical' body vis-à-vis the 'lived' body that would somehow be more pure (ibid.; Mol, 2002).

In her contribution, Irma Van der Ploeg deconstructs in great detail all the operations that allow for the constitution of new 'body collectives' ('couple' and 'fetus'), in fertily treatments and fetal surgery. She shows how these medical practices and their accompanying discursive mechanisms render the treatment of male or fetal problems through interventions on women's bodies acceptable or even inevitable. But her main point is political as well as methodological. To develop a critical analysis of technologies and practices, to be able to fruitfully ask the question of patient autonomy and bodily integrity, one has to suspend the definition of what counts as individuality, which can no longer be equated with the boundaries of the individual body, and to describe variations of what it includes.

A related yet subtly different interpretation of the body politics and the "body collective' is given by Steve Epstein's work. Epstein focuses on the debates about the US 1993 NIH Revitalization Act, and especially about those paragraphs that require that women and members of racial and ethnic minority groups are "included as subjects" in each clinical study funded by the US National Institutes of Health. These debates, Epstein convicingly argues, are all about when bodies can be counted as 'the same' or have to be seen as 'different', and about what 'differences' should be seen to be relevant enough to count as biologically grounded, distinctive 'categories' of bodies. These debates are highly politically charged, since they are simultaneously about whether collective identities are and should be underpinned by biological differences - and about which differences matter and which not. As in van der Ploeg's article, then, Epstein argues that what counts as the biological body is a thoroughly political question, drawing novel lines around and between individuals that separate and join them in novel, ever contested ways. 
In the final article, Bruno Latour draws together several of the themes brought up throughout the special issue in a novel interpretation of the question what counts as ' $\mathrm{good}$ science' in general, and about 'bodies' in particular. Bodies, he argues, come into being through being affected by other bodies, instruments, experiences: the more profoundly the body has been articulated with all these surrounding entities, the richer, the more collective and therefore more 'real' - it is. What, however, is a 'good' articulation? When the 'natural' body is lost to us as a starting point, how do we distinguish 'good' ways of performing bodies from 'bad' ways? Drawing upon the work of Isabelle Stengers (e.g. 1997) and Despret (this volume), and following a strategy similar to authors such as Haraway (e.g. 1989), Latour takes an epistemological approach to this question. Picking up a trope that has been somewhat neglected in STS since the the demise of the prescriptive philosophy of science (with Popper and Lakatos being the last 'heroes'), he pleads for a novel 'shibboleth' to distinguish 'good' science from 'bad'. As science itself, he argues, this falsification principle cannot avoid being simultaneously political and about 'truth': any epistemology is necessarily a political epistemology. To return to the question of 'bodies', any judgment about what counts as a 'scientific' mode of talking about 'bodies' is simultaneously a judgment about what types of bodies should populate our worlds, and how feasible it is to construct alternative articulations, to perform bodies differently. Addressing this question in the light of the ever increasing importance of 'bio-politics', the definition, modification and commodification of 'life' in all its forms, his article forms a fitting open end to this special issue.

This special issue, Bodies on Trial, then, first of all puts our understanding of 'bodies' to trial. What can we do, theoretically and politically, with this category? How do the modifications that the authors combined here propose matter to this question? How is the 'body' affected by its confrontation with STS? In its turn, of course, STS is put to trial as well: will the rephrasings it offers to the social study of the bodies proof to be viable? Most importantly, however, Bodies on Trial presents the body as being shaped, brought into being, transformed and known through interactions with other entities (multiple substances and interventions in the case of diabetes, resuscitation technologies, methadone, multiplicity of representations in patient records, birth technologies, odor kits and so forth). The 'lived body' is not reduced by its encounters with things and technologies - rather, these encounters are what brings it to its specific life. Such trials are what performs bodies; such trials embody us. 


\section{Endnotes}

\section{References}

Armstrong, D (1983) Political Anatomy of the Body. Medical Knowledge in Britain in the Twentieth Century. Cambridge: Cambridge University Press.

Balsamo, A. (1992) 'On the cutting edge: cosmetic surgery and the technological production of the gendered body’ Camera Obscura 28: 207-38.

Barad, K (1996) 'Meeting the Universe Halfway: Realism and Social Constructivism without Contradiction' in L. H. Nelson, and J. Nelson (eds.) Feminism, Science and the Philosophy of Science, Dordrecht: Kluwer: 161-94.

Berg, M., and A. Mol (eds.) (1998) Differences in Medicine. Unraveling Practices, Techniques and Bodies. Durham: Duke University Press.

Berthelot, J.-M (1994) 'The Body as Discursive Operator: Or the Aporias of a Sociology of the Body’ Body \& Society 1: 13-23.

Bijker, W. E., and J. Law (eds.) (1992) Shaping Technology - Building Society. Studies in Sociotechnical Change. Cambridge: MIT Press.

Butler, J (1993) Bodies That Matter. On the Discursive Limits of 'Sex'. London: Routledge. 481-507.

Callon, M., and J. Law (1995) 'Agency and the Hybrid Collectif' South Atlantic Quarterly 94:

Cartwright, L. (1995) Screening the Body. Tracing Medicine's Visual Culture. Minneapolis: University of Minnesota Press. London: Sage.

Collins, H. M. (1985) Changing Order: Replication and Induction in Scientific Practice.

Duden, B. (1991) The woman beneath the skin: A doctor's patients in eigheenth-century Germany. Cambridge: Harvard.

Featherstone, M., M. Hepworth, and B. S. Turner (1991) The body. Social process and cultural theory. London: Sage.

Frank, A. W. (1996) 'Reconciliatory Alchemy: Bodies, Narratives and Power' Body \& Society 2 (3): 103-109.

Frank, A. W. (1997) 'Narrative Witness to Bodies: A Response to Alan Radley' Body \& Society 3 Routledge.

Franklin, S. (1997) Embodied Progress: A Cultural Account of Assisted Conception. New York:

Haraway, D. (1989) Primate Visions: Gender, Race, and Nature in the World of Modern Science. New York: Routledge. Routledge.

Haraway, D. J. (1991) Simians, Cyborgs, and Women: The Reinvention of Nature. New York:

Haraway, D. J. (1994) 'A Game of Cat's Cradle. Science Studies, Feminist Theory, Cultural Studies’ Configurations 1: 59-71. 
Harrison, W. C. and Hood-Williams, J. (1997) 'Gender, Bodies and Discursivity: A Comment on Hughes and Witz' Body \&Society 3 (4): 103-118.

Hausman, B. L. (1995) Changing Sex. Transexualism, Technology, and the Idea of Gender. Duke University Press.

Hayles, N. K. (1992) 'The Materiality of Informatics' Configurations 1: 147-70.

Hayles, N. K. (1997) 'The Posthuman Body: Inscription and Incorporation in Galatea 2.2 and Snow Crash' Configurations 5: 241-266.

Heath, D., and P. Rabinow (1993) 'Bio-Politics: The Anthropology of the New Genetics and Immunology' Special Issue. Culture, Medicine and Psychiatry 17: 319.

Hirschauer, S. (1991) 'The Manufacture of Bodies in Surgery' Social Studies of Science 21: 279-

Hood-Williams, J. (1996) 'Goodbye to Sex and Gender’ The Sociological Review. 44 : 1-16.

Hughes, A. and Witz, A. (1997) 'Feminism and the Matter of Bodies: From de Beauvoir to Butler' Body \&Society 3 (1): 47-60.

Jacobus, M., E. F. Keller, and S. Shuttleworth, (eds.) (1990) Body/Politics: Women and the Discourses of Science. New York: Routledge.

Kapsalis, T. (1997) Public privates. Performing Gynecology from both Ends of the Speculum. Durham: Duke University Press.

Kelly, M. P., and D. Field (1996) 'Medical sociology, chronic illness and the body' Sociology of Health and Illness 18: 241-257.

Knorr-Cetina, K. (1999) Epistemic Cultures: How the Sciences Make Knowledge. Cambridge: Harvard University Press.

Knorr-Cetina, K. (1999) Epistemic Cultures: How the Sciences Make Knowledge. Cambridge: Harvard University Press.

Komesaroff, P. A. (ed.) (1995) Troubled Bodies: Critical Perspectives on Postmodernism, Medical Ethics, and the Body. Durham: Duke University press.

Laqueur, T. (1990) Making Sex. Body and Gender from the Greeks to Freud. Cambridge: Harvard University Press.

Latour B. (1987) Science in action. Cambridge: Cambridge University Press.

Latour, B. (1996) 'On Interobjectivity’ Mind, Culture and Activity 3: 228-245.

Latour, B. (1999) Pandora's Hope : Essays on the Reality of Science Studies. Cambridge: Harvard University Press.

Latour B, Woolgar S. (1986) Laboratory Life. The Construction of Scientific Facts. 2nd ed. Princeton, N.J.: Princeton University Press. 267-92.

Lock, M. (1997) 'Decentering the Natural Body. Making Difference Matter' Configurations 5: London: Sage.

Lupton, D. (1994) Medicine as Culture. Illness, disease and the body in Western societies.

Lynch, M. (1993) Scientific practice and ordinary action: ethnomethodology and social studies of science. New York: Cambridge University Press.

Mamo, L. and Fishman, J. R. (2001) 'Potency in All the Right Places: Viagra as a Technology of the Gendered Body' Body \&Society 7 (4): 13-35.

Martin, E. (1991) 'The egg and the sperm: how science has constructed a romance based on stereotypical male-female roles' Sign 16: 485-501.

Martin, E. (1994) Flexible Bodies. Boston: Beacon. 
Press.

Mol, A. (2002) The Body Multiple. Ontology in Medical Practice. Durham: Duke University

Moore, L. J. C., Adele E. (2001) 'The Traffic in Cyberanatomies : Sex/Gender/Sexualities in Local and Global Formations' Body \& society 7: 57-96. Routledge.

Oudshoorn, N. (1994) Beyond the natural body: an archeology of sex hormones. London:

Park, K (1997) 'The rediscovery of the clitoris' in: C. Mazzio and D. Hillman, The Body in Parts: Fantaisies of Corporeality in Early Modern Europe. New York: Routledge.

Pickering, A. (ed.) (1992) Science as Practice and Culture. Chicago: University of Chicago Press.

Pitts, V. L. (1998) 'Reclaiming' the Female Body: Embodied Identity Work, Resistance and the Grotesque' Body \&Society 4 (3): 67-84. 93-101.

Radley, A. (1997) 'The Triumph of Narrative? A Reply to Arthur Frank' Body \& Society 3 (3):

Shilling, C. (1993) The Body and Social Theory. London: Sage.

Stengers, I. (1997) Power and Invention: Situating Science. Minneapolis: University of Minnesota Press.

Thacker, E. (1999) 'Performing the Technoscientific Body: RealVideo Surgery and the Anatomy Theater' Body \&Society 5 (2-3): 317-336.

Turner, B. S. (1992) Regulating bodies. Essays in medical sociology. London: Routledge.

Waldby, C. (1997) 'Revenants: The Visible Human Project and the Digital Uncanny' Body \&Society 3 (1): 1-16.

74.

Waldby, C. (2000) 'Fragmented bodies, incoherent medicine' Social studies of science 30 (3): 465-

Witz, A. (2000) 'Whose Body Matters? Feminist Sociology and the Corporeal Turn in Sociology and Feminism' Body \& society 6(2): 1-24.

1 See e.g. Turner (1992), Kelly and Field (1996), Berthelot (1994), Martin (1991, 1994), Cartwright (1995), Lock (1997)

2 Butler (1993), Hood-Williams (1996, Hughes and Witz (1997, Pitts (1998, Witz (2000), Harrison and Hood-Williams (1997). On the question of gender, sex and medical sciences : Laqueur (1990, Hausman (1995), Park (1997), Moore (2001), Mamo and Fishman (2001).

${ }^{3}$ See respectively e.g. Armstrong (1983), Martin (1994), Heath and Rabinow (1993) and Lupton (1994); Haraway (1991), Balsamo (1992), Franklin (1997) and Butler (1993); Shilling (1993) and Featherstone, Hepworth and Turner (1991), and the discussion between Frank and Radley : Frank (1996), Radley (1997), Frank (1997).

${ }^{4}$ Collins (1985), Knorr-Cetina (1981), Latour and Woolgar (1986) and Latour (1987).

${ }^{5}$ See e.g. Latour (1987), Bijker and Law (1992), Pickering (1992), Knorr-Cetina (1999). 
${ }^{6}$ See e.g. Duden (1991) and Jacobus et al. (1990).

${ }^{7}$ See e.g. Latour (1999), Knorr-Cetina (1999), Lynch (1993), Haraway (1991), Pickering (1992) and Bijker and Law (1992).

${ }^{8}$ See e.g. Hirschauer (1991), Haraway (1994), Oudshoorn (1994), Latour (1996).

${ }^{9}$ See for a subtle exploration of this epistemological position in general Barad (1996), and see Duden (1991) and Hayles $(1992,1997)$ for similar positionings. Butler is obviously a central author in this search for a 'material' yet historized conception of bodies. In her careful avoidance of an a-historical approach, however, she seems to turn 'matter' itself into a discursive category (Butler 1993).

${ }^{10}$ See e.g. Mol (2002), Hirschauer (1991), Thacker (1999), Waldby (1997), Waldby (2000).

${ }^{11}$ In this specificity lies the difference with analysis such as Terry Kapsalis (1997): the list of what counts to define each situation is more open-ended than in the ritualised situations described by Kapsalis. 